\title{
Incorporating Low-Cost Seismometers into the Central Weather Bureau Seismic Network for Earthquake Early Warning in Taiwan
}

\author{
Da-Yi Chen ${ }^{1,2}$, Yih-Min Wu ${ }^{1, *}$, and Tai-Lin Chin ${ }^{3}$ \\ ${ }^{1}$ Department of Geosciences, National Taiwan University, Taipei, Taiwan, R.O.C. \\ ${ }^{2}$ Central Weather Bureau, Taipei, Taiwan, R.O.C. \\ ${ }^{3}$ Department of Computer Science and Information Engineering, National Taiwan University of Science and Technology, Taipei, \\ Taiwan, R.O.C.
}

Received 8 October 2014, revised 25 March 2015, accepted 17 April 2015

\begin{abstract}
A dense seismic network can increase Earthquake Early Warning (EEW) system capability to estimate earthquake information with higher accuracy. It is also critical for generating fast, robust earthquake alarms before strong-ground shaking hits the target area. However, building a dense seismic network via traditional seismometers is too expensive and may not be practical. Using low-cost Micro-Electro Mechanical System (MEMS) accelerometers is a potential solution to quickly deploy a large number of sensors around the monitored region. An EEW system constructed using a dense seismic network with 543 MEMS sensors in Taiwan is presented. The system also incorporates the official seismic network of Taiwan's Central Weather Bureau (CWB). The real-time data streams generated by the two networks are integrated using the Earthworm software. This paper illustrates the methods used by the integrated system for estimating earthquake information and evaluates the system performance. We applied the Earthworm picker for the seismograms recorded by the MEMS sensors (Chen et al. 2015) following new picking constraints to accurately detect P-wave arrivals and use a new regression equation for estimating earthquake magnitudes. An off-line test was implemented using 46 earthquakes with magnitudes ranging from $\mathrm{M}_{\mathrm{L}} 4.5$ - 6.5 to calibrate the system. The experimental results show that the integrated system has stable source parameter results and issues alarms much faster than the current system run by the CWB seismic network (CWBSN).
\end{abstract}

Key words: Earthquake early warning, MEMS accelerometer, Seismic Network

Citation: Chen, D. Y., Y.M. Wu, and T. L. Chin, 2015: Incorporating low-cost seismometers into the Central Weather Bureau seismic network for Earthquake Early Warning in Taiwan. Terr. Atmos. Ocean. Sci., 26, 503-513, doi: 10.3319/TAO.2015.04.17.01(T)

\section{INTRODUCTION}

The Earthquake Early Warning (EEW) system issues timely warnings before the earthquake produces catastrophic damage in the protected area. There are two types of EEW systems. The first is an on-site EEW system with seismometers deployed in the protected area. This kind of system uses P-wave information, which propagates faster, to predict the later $\mathrm{S}$ waves which have larger amplitudes. The second type is the regional EEW system in which the seismometers are deployed in remote sites away from the protected area. This kind of system uses information from those seismometers near the epicenter to determine certain source parameters and then issue warnings to the target

\footnotetext{
* Corresponding author

E-mail:drymwu@ntu.edu.tw
}

area. A number of EEW systems have been run and tested in many countries where seismic hazards occur frequently (Allen et al. 2009).

Taiwan is located in one of the most active seismic zones in the world. The Philippine Sea Plate moves toward the Eurasia Plate by approximately $7 \mathrm{~cm}$ per year (Yu et al. 1997), causing many earthquakes in Taiwan (Shin and Teng 2001; Wu et al. 2003, 2008; Wen et al. 2008; Huang et al. 2010, 2011; Chen et al. 2013). Therefore, it is important for Taiwan to develop a reliable EEW system to provide early earthquake warning. Over the past few years experimental regional EEW systems have been tested and operated in Taiwan. Wu and Teng (2002) implemented the Virtual SubNetwork (VSN) concept, which achieves a 22-sec reporting time (the time between the earthquake occurrence and EEW system warning). The P-wave method (Wu and Zhao 2006) 
was proposed and tested to reduce the reporting time (Hsiao et al. 2009, 2011). The Central Weather Bureau (CWB) recently integrated its seismic network into the Earthworm platform, a program originally developed by the United States Geological Survey (USGS) (Johnson et al. 1995). Based on the CWB experimental platform, an EEW prototype system based on Earthworm has been tested since 2007 (Hsiao et al. 2011; Chen et al. 2012). EEW test alarms were delivered to all elementary and junior high schools around Taiwan since January 2014 (Chen et al. 2015).

Some experimental on-site EEW systems have been tested and operated as well. Wu et al. (2006) determined the relationships between the earthquake magnitude and characteristic parameters from the first three seconds of the P-wave. They demonstrated that a single-station approach can be used to estimate earthquake magnitudes well. Wu et al. (2011) demonstrated that the on-site EEW system can provide valuable information to the Taiwan High Speed Railway during the 2010 Jia-Sian earthquake. The National Center for Research on Earthquake Engineering (NCREE) developed a neural network method for predicting structural response in an on-site EEW system (Lin et al. 2011a). The on-site EEW system was put into practice in elementary schools in Taiwan (Lin 2011).

The station coverage gap, also called GAP, defined as the angle between the epicenter and two adjacent stations, can be used as a metric for evaluating the quality of an EEW report (Wu et al. 1997, 2013a). A dense seismic network can provide a sufficient number of trigger stations for good seismic station coverage (e.g., a small value of GAP) within a relatively short time after an earthquake. Therefore, it can be a potential solution to provide faster and more reliable EEWs. However, it is expensive to deploy a large number of traditional seismic stations. Fortunately, recent advances in electrical and mechanical technologies have made it possible to build low-cost seismometers [Micro Electro Mechanical System (MEMS) sensors] for constructing dense seismic networks. Holland (2003) first monitored earthquakes using seismic data streams from low-cost seismometers and short-period seismic sensors. The home seismometer concept has been implemented in Japan (Horiuchi et al. 2009). The Quake Catcher Network (QCN) project plans to rapidly expand and increase the density of ground-motion observations with relative low cost (Cochran et al. 2009). The QCN initiated Rapid Aftershock Mobilization Programs (RAMP) following the 2010 M 8.8 Maule, Chile, earthquake (Chung et al. 2011) and the 2010 M 7.2 Darfield, New Zealand, earthquake (Lawrence et al. 2014), respectively. The results demonstrated that the QCN method can be used to detect and locate moderate to large earthquakes and estimate their magnitudes using ground-motion parameters. The Selforganizing Seismic Early Warning Information Network (SOSEWIN) was tested in Istanbul based on wireless communications (Fleming et al. 2009). National Taiwan Uni- versity (NTU) and San Lien Corporation, a high-tech oriented company (http://www.sanlien.com.tw), developed an accelerometer, named Palert, based on MEMS technology. The Palert Seismic Network (PSN) was tested and operated for both on-site and regional EEW systems by NTU since 2010. The Palert system is capable of providing high quality, stable data streams for earthquake monitoring (Wu et al. 2013b; Hsieh et al. 2014; Wu 2015).

PSN is a low-cost, high-density regional seismic network that monitors large earthquakes in Taiwan. The realtime seismic data streams generated by PSN are open for academia research. The data collected by PSN has been demonstrated useful for seismic intensity map determination for emergency management agencies (Wu et al. 2013b). Additionally, CWB has operated dense CWB seismic network (CWBSN) to monitor earthquake activities for more than 20 years in Taiwan (Shin 1993; Wu et al. 1997, 2008). CWB further improves the quality of seismic data by deploying borehole seismometers with upgraded digitizers for strong-motion and short-period sensors into 100 samples per second and 24 bits in resolution. CWB has also enlarged the station coverage by combining real-time data streams from other institutions and constructed a cable-based ocean bottom seismometer in the eastern offshore area, which is the most active seismic zone in Taiwan (Chen et al. 2015). PSN and CWBSN are run by NTU and CWB, respectively. It is wasteful to run two independent systems in the same area. On the other hand, if the two systems can be combined to create a system with a denser seismic network the system output quality from any earthquakes occurring in this area will be improved. This paper shows experiments from the two integrated systems. This is the first time in the world a low-cost seismic network has been integrated with a traditional seismic network in an EEW system.

In PSN the Palerts are installed at elementary school buildings, usually set up on a wall or pillar. Human activities transmit noise to the Palerts. As a result some Palerts may record artificial waveforms and the automatic P-wave phase picking procedure may fail. Therefore, we adopted an Earthworm's picker (Chen et al. 2015) following new picking constraints to obtain high quality $\mathrm{P}$-wave detections at elementary schools. The shaking caused by earthquakes will vibrate buildings. Because Palerts are installed in buildings the waveforms recorded by Palerts are affected by the building effects. These effects may cause earthquake magnitude over estimation. We established an empirical relationship between the amplitudes, magnitudes and hypocenter distances to correct for the over estimations. Moreover, we investigate the performance of the integrated seismic network (ISN) in terms of earthquake location determination, earthquake magnitude estimation and reporting time. The ISN EEW system (ISN-EEW) and the CWBSN EEW system (CWBSN-EEW) are tested and compared by performing off-line simulations using real data from 46 events with 
magnitudes ranging from $4.5-6.5$.

\section{THE INTEGRATED SEISMIC NETWORK}

The main purpose of the CWBSN is to monitor seismic activities around the Taiwan region. The data transmission has evolved from telephone line telemetry in the late 2011 to Internet based telemetry (Chang et al. 2012). The CWBSN consists of four types of seismic stations including six-channel seismic stations, broadband seismic stations, borehole seismic stations and one cable-based ocean bottom seismic station (Shin et al. 2013; Hsiao et al. 2014; Chen et al. 2015). Figure 1a shows the CWBSN station distribution incorporated with real-time seismic data streams from the Institute of Earth Sciences (IES) Academia Sinica and the Incorporated Research Institutions of Seismology (IRIS). The real-time seismic signals, digitized at a 24-bit resolution and time stamped by the Global Position System (GPS), are packed and transmitted to CWB headquarters in Taipei via the Internet. Except for the IRIS signal, which has a frequency of 20 samples per second, all other signals have a frequency of 100 samples per second.

The PSN consists of 543 low-cost accelerometers, transmits three-component real-time data streams, i.e., the $\mathrm{x}, \mathrm{y}$, and $\mathrm{z}$ axis data streams, back to the data processing center for regional EEW. The Palert device can sample earthquake shaking at a frequency of $100 \mathrm{~Hz}$. The sampled data are digitized with 16-bit resolution between -2 and $+2 \mathrm{~g}$ dynamic range, and time stamped by the Network Time Protocol (NTP) server through the Internet. Figure $1 \mathrm{~b}$ shows the PSN station distribution. Most of the devices are installed onto walls or pillars at elementary schools. Real-time data are packed at one-second duration and transmitted via the Internet. Each Palert accelerometer can transmit data to two servers located at NTU and the Academia Sinica Grid Computing (ASGC) Centre. Figure 2 shows that PSN and CWBSN are integrated by the Earthworm platform. Although the CWBSN seismic sensors are made by different manufacturers, the corresponding modules can be found in Earthworm for receiving data streams from field seismic stations or other data centers.

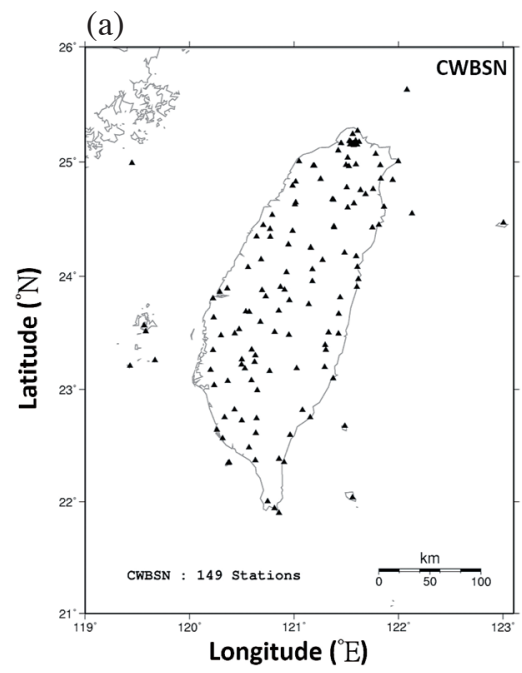

(b)

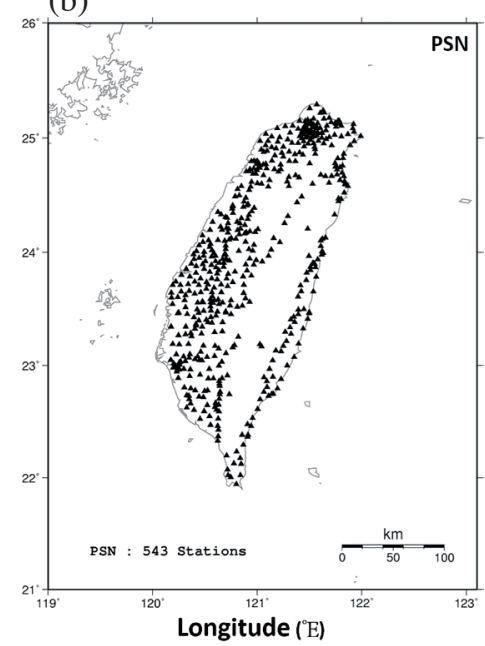

Fig. 1. The station distributions for the two seismic networks. (a) The Central Weather Bureau Seismic Network (CWBSN) station distribution, (b) the Palert Seismic Network (PSN) station distribution.

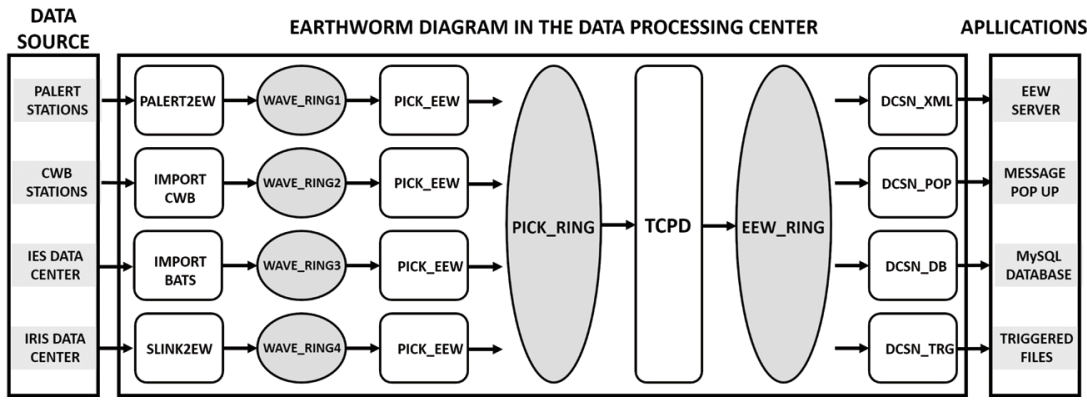

Fig. 2. A schematic diagram of the data processing. The first part is the data source which provides real-time seismic data streams from different kind of seismic sensors and other institutions. The middle part is the data processing procedure in the Earthworm system at the data center. The last part is the applications which receive information from the middle part and use the information. 


\section{THE EEW SYSTEM CONFIGURATION}

EEW systems process real-time seismic data to capture P-wave arrival onset, determine the triggered waveform amplitudes and calculate the earthquake location and magnitude. Warnings are issued to the target areas through a decision making procedure. Three Earthworm modules are included in the EEW system, including the PICK_EEW module for P-wave auto-picking, the TCPD module for earthquake magnitude and location determination and the DCSN module for warning reporting (Chen et al. 2015). Figure 2 shows the EEW system configuration in which only the vertical seismic waveform components are used. Each waveform packet in the Earthworm platform is temporally stored in a shared memory, called WAVE_RINGs, which has a limited size and only keeps the latest data. The PICK EEW module detects P-wave arrivals and obtains the peak amplitude in displacement $(\mathrm{Pd})$ of the initial $\mathrm{P}$-waves within a three-second time window. The detected parameters are then sent into another shared memory, called PICK_RING, in which the TCPD module uses the stored parameters for generating the EEW report including the earthquake origin time, location and magnitude. The DCSN module then takes the EEW report from the EEW_RING for other applications such as generating the XML-formatted messages for clients running the EEW display and warning program provided by the CWB (Chen et al. 2015). The DCSN module will also pop up EEW messages on the corresponding CWB staff computers, insert EEW messages into the MySQL database and archive the triggered seismic waveforms.

When a large earthquake occurs and the seismic wave propagates away from the epicenter, the number of triggered seismic stations will increase with time. The EEW system will update the EEW report along with the triggered seismic stations. However, in the early stage the EEW report may contain a large location discrepancy because only a few stations were triggered. Other metrics should therefore be used to ensure that the EEW report is reliable. The GAP is one of the key factors used to determine if the earthquake location report is good enough when the earthquake is inside a seismic network (Wu et al. 1997, 1999, 2013b). In the earthquake localization process, the localization error can be reduced with a small GAP value. An EEW system normally updates its report along with the increase in triggered stations since the GAP value decreases. It is necessary to find suitable criteria for obtaining an EEW report with relatively low GAP and low reporting time.

We analyzed the data set from the online CWBSNEEW (Hsiao et al. 2011; Chen et al. 2012, 2015). One hundred and seventeen earthquakes were detected by the system from January to August 2014. Figure 3a shows the relation between the EEW report order and the number of triggered stations. Figure $3 \mathrm{~b}$ shows the relation between the EEW report order, the reporting time and the GAP. Generally, the GAP decreases along with the increase in EEW reports but the reporting time increases. We found an intercept in Fig. 3b that shows the fifth EEW report could be a good point for determining acceptable source parameters. In order to obtain a specific proxy for the criteria, Fig. 3a shows that the fifth report needs at least 13 triggered stations on average. Therefore, in this study, the CWBSN-EEW will issue reports when the number of triggered station is at least 13. In addition, to generate more stable ISN-EEW results we chose EEW reports with GAP equal to or less than the number of reports generated by the CWBSN-EEW.

\section{MAGNITUDE ESTIMATION USING PALERTS}

A reliable estimation of earthquake magnitude for the EEW system depends on two primary factors. The first is a robust picker for precisely detecting $\mathrm{P}$-wave onset time and intelligently avoiding the noise. The second is a statistically significant regression equation for predicting earthquake magnitudes using only the initial portion of P-waves. Palerts installed in elementary school buildings may be affected by human activities and the amplitude may be amplified by building responses. Therefore, we adopted the Earthworm picker (Chen et al. 2015) following new picking constraints for better determining $\mathrm{P}$-wave onset time and preventing false picks caused by noise. We also constructed a new regression (a)

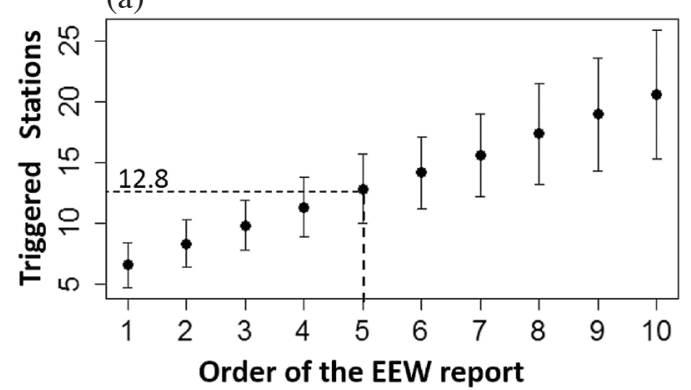

(b)

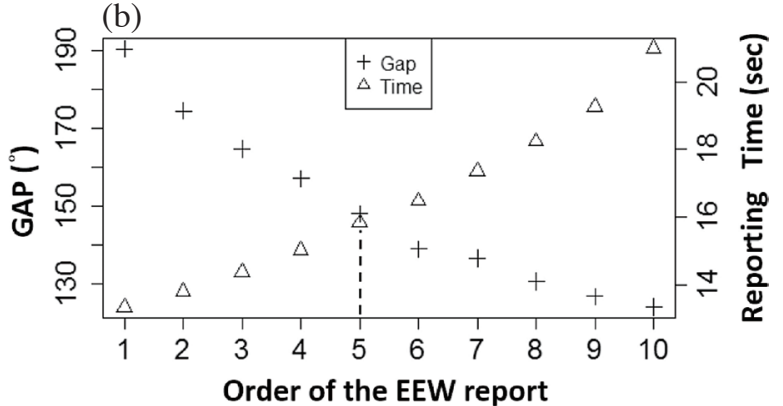

Fig. 3. Relationships between the Earthquake Early Warning (EEW) parameters. (a) Relationships between the EEW report order and the triggered stations; (b) relationships between the EEW report order, the reporting time and the GAP. 
equation to produce better earthquake magnitude prediction.

To ensure every P-wave picks from Palerts with high quality is crucial for the EEW system we applied the P-wave picking algorithms from the Earthworm module, PICK_ EEW, (Chen et al. 2015), and followed new picking constraints with three parameters, XON, XP0 and XP1, for evaluating the pick quality. $\mathrm{XON}$ is the first filtered data deference at pick time. XP0 is the first maximum filtered data from the preceding half cycle. XP1 is the second maximum filtered data from the preceding half cycle. All of them are normalized using 1.6 times the running mean absolute filtered data value. Each valid pick generated from Palerts should be satisfied by one of the following two criteria. The first is that either XP0 or XP1 should be larger than 13.0 and XON should be larger than 3.0. The second is that either XP0 or XP1 should be larger than 20.0 and XON should be larger than 0.8 . Figure 4 a shows examples illustrating picks corresponding to the criteria considered high quality. In contrast, Fig. 4b shows examples illustrating picks that were considered poor quality. These criteria are quite useful in evaluating the quality of picks detected by Palerts.

We used 46 events to correct the errors in seismograms recorded by Palerts amplified by the building response, shown in Table 1, including 649 vertical-component records to determine $\mathrm{Pd}$, which is the peak amplitude of the initial $\mathrm{P}$-wave displacement within a 3 -second time window. The seismograms recorded by Palerts were integrated twice to obtain the displacement and then a $0.075 \mathrm{~Hz}$ high-pass recursive Butterworth filter was applied to remove the lowfrequency drift after the numerical integration. Each P-wave arrival was verified manually to ensure good quality for constructing an empirical formula between the Pd values and earthquake magnitudes. We assumed a linear relationship among the logarithmic Pd, the magnitude $\mathrm{M}$ and the logarithmic hypocentral distance R: $\log \mathrm{Pd}(\mathrm{R})=\mathrm{A}+\mathrm{B} \cdot \mathrm{M}+\mathrm{C} \cdot \log (\mathrm{R})$

where $\mathrm{A}, \mathrm{B}$, and $\mathrm{C}$ are constants to be determined from the regression analysis using the $\mathrm{P}$-waves from the 46 events. We used R software (R Development Core Team 2011) in the regression analysis to detect and remove outliers within the data. The model was then fit to the data. The best-fitting attenuation relationship for $\log \mathrm{Pd}$ was found to be

$\log \mathrm{Pd}(\mathrm{R})=-2.797+0.404 \cdot \mathrm{M}-0.539 \cdot \log (\mathrm{R}) \pm 0.33$

Equation (2) was used for estimating earthquake magnitudes using vertical-component $\mathrm{P}$-waves recorded by Palerts.

\section{THE OFF-LINE TEST}

ISN-EEW, in off-line mode, was used to test the integrated system using seismic waveforms with magnitudes greater than 4.5, depths less than $40 \mathrm{~km}$, and epicenters within $40 \mathrm{~km}$ collected from the coastline of Taiwan from 2013 to January 2015. Table 1 shows the dataset consisting of 46 events including three events with magnitudes between 6.0 and 6.5. The off-line simulation results were compared with those generated by the CWBSN-EEW.

In the off-line test the ISN-EEW used the same Earthworm's picker but different criteria to detect P-wave arrivals for the P-waves recorded by the CWBSN and the ISN. Figure 5 shows a comparison of the source location errors between the CWBSN-EEW and the ISN-EEW. The difference in location error for CWBSN-EEW and ISN-EEW is $0.3 \mathrm{~km}$. For the depth error the ISN-EEW is a little better than the CWBSN-EEW. This implies that ISN-EEW can produce stable earthquake location results.

The Pd values from the CWBSN are used to estimate (a)

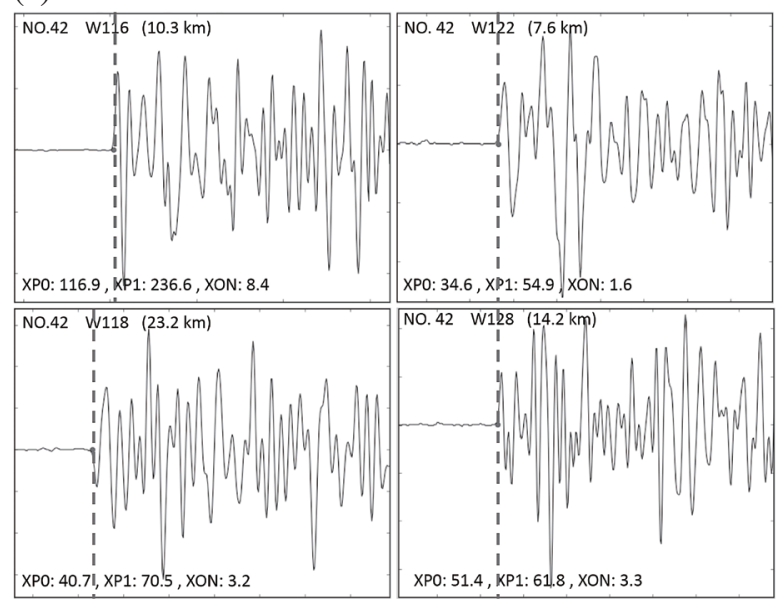

(b)

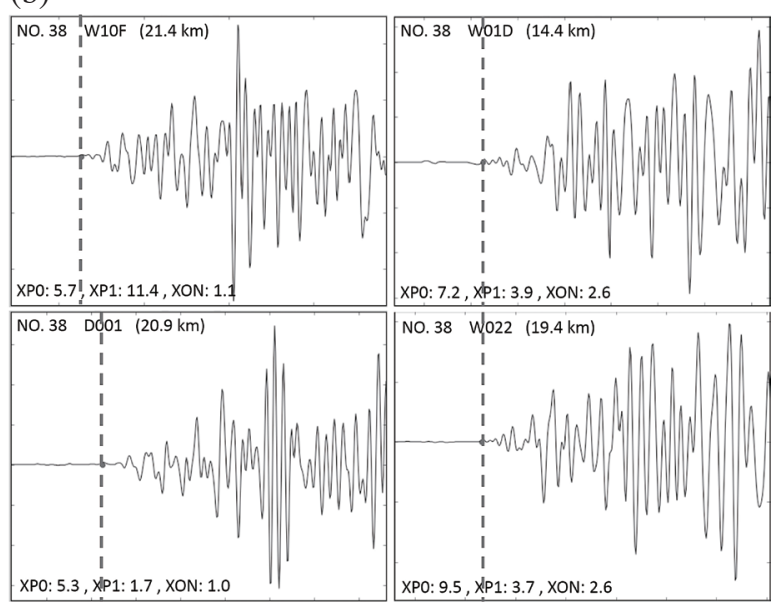

Fig. 4. Examples of the automatic P-wave arrival detection. (a) High quality picks. The parameters XP0, XP1, and XON are over the criteria; (b) poor quality picks. The parameters XP0, XP1, and XON are under than the criteria. 
Table 1. The source parameters for the offline test and comparisons of CWBSN-EEW and ISN-EEW for the offline test.

\begin{tabular}{|c|c|c|c|c|c|c|c|c|c|c|c|c|c|}
\hline \multirow[b]{2}{*}{$\begin{array}{c}\text { Event } \\
\text { NO. }\end{array}$} & \multirow[b]{2}{*}{$\begin{array}{c}\text { Date }(\mathrm{mm} / \\
\mathrm{dd} / \mathrm{yy})\end{array}$} & \multirow[b]{2}{*}{$\begin{array}{c}\text { Latitude } \\
\left({ }^{\circ}\right) \\
\end{array}$} & \multirow[b]{2}{*}{$\begin{array}{l}\text { Longi- } \\
\text { tude }\left({ }^{\circ}\right) \\
\end{array}$} & \multirow[b]{2}{*}{$\begin{array}{c}\text { Depth } \\
(\mathbf{k m})\end{array}$} & \multirow[b]{2}{*}{$\mathbf{M}_{\mathrm{L}}$} & \multicolumn{2}{|c|}{ Time } & \multicolumn{2}{|c|}{ Gap } & \multicolumn{2}{|c|}{ Epicenter Error } & \multicolumn{2}{|c|}{$\begin{array}{l}\text { NO. of Stations } \\
\text { for ISN-EEW }\end{array}$} \\
\hline & & & & & & $\begin{array}{l}\text { CWBSN- } \\
\text { EEW (sec) }\end{array}$ & $\begin{array}{c}\text { ISN-EEW } \\
\text { (sec) }\end{array}$ & $\begin{array}{l}\text { CWBSN- } \\
\text { EEW }\left({ }^{\circ}\right)\end{array}$ & $\begin{array}{c}\text { ISN-EEW } \\
\left({ }^{\circ}\right) \\
\end{array}$ & $\begin{array}{l}\text { CWBSN- } \\
\text { EEW (km) }\end{array}$ & $\begin{array}{c}\text { ISN-EEW } \\
(\mathbf{k m})\end{array}$ & Total & Palert \\
\hline 1 & $01 / 02 / 13$ & 121.74 & 23.97 & 7 & 4.7 & 17.8 & 18 & 204 & 197 & 4.0 & 3.0 & 26 & 1 \\
\hline 2 & 01/03/13 & 121.73 & 23.99 & 7 & 4.7 & 14.5 & 14.5 & 219 & 219 & 3.2 & 4.3 & 18 & 2 \\
\hline 3 & $01 / 17 / 13$ & 121.98 & 24.44 & 14 & 5.1 & 13.2 & 12.2 & 181 & 177 & 1.3 & 1.9 & 18 & 8 \\
\hline 4 & $02 / 17 / 13$ & 121.45 & 24.32 & 6 & 4.6 & 11.8 & 12.5 & 143 & 108 & 1.9 & 2.4 & 11 & 3 \\
\hline 5 & $02 / 19 / 13$ & 120.55 & 23.35 & 15 & 4.6 & 18.2 & 12.1 & 65 & 40 & 1.9 & 0.8 & 37 & 21 \\
\hline 6 & $02 / 19 / 13$ & 120.60 & 22.91 & 16 & 4.7 & 14.1 & 9.8 & 158 & 82 & 5.3 & 1.4 & 13 & 11 \\
\hline 7 & $02 / 20 / 13$ & 121.39 & 23.23 & 20 & 4.5 & 15.2 & 15.4 & 156 & 148 & 3.4 & 2.1 & 16 & 3 \\
\hline 8 & $03 / 04 / 13$ & 121.33 & 23.00 & 24 & 4.6 & 14.8 & 11.1 & 177 & 173 & 4.0 & 5.4 & 16 & 4 \\
\hline 9 & 03/07/13 & 121.46 & 24.30 & 6 & 5.9 & 14.1 & 12.1 & 69 & 69 & 1.3 & 1.1 & 16 & 4 \\
\hline 10 & $03 / 07 / 13$ & 121.45 & 24.34 & 6 & 4.6 & 13.7 & 13.6 & 69 & 69 & 1.6 & 1.6 & 20 & 3 \\
\hline 11 & $03 / 20 / 13$ & 121.95 & 24.45 & 12 & 4.6 & 18.9 & 19.4 & 149 & 145 & 0.5 & 2.9 & 60 & 15 \\
\hline 12 & $03 / 27 / 13$ & 121.05 & 23.90 & 19 & 6.2 & 9.8 & 9.8 & 102 & 82 & 1.5 & 0.8 & 21 & 16 \\
\hline 13 & $03 / 27 / 13$ & 121.00 & 23.93 & 14 & 4.5 & 11.8 & 7.4 & 96 & 67 & 1.3 & 1.5 & 11 & 6 \\
\hline 14 & $05 / 21 / 13$ & 121.77 & 24.28 & 14 & 4.9 & 12.3 & 12.2 & 199 & 188 & 2.1 & 3.3 & 19 & 6 \\
\hline 15 & $06 / 01 / 13$ & 121.27 & 22.04 & 32 & 5.0 & 23.2 & 25.4 & 271 & 251 & 10.3 & 8.0 & 22 & 1 \\
\hline 16 & $06 / 02 / 13$ & 120.97 & 23.86 & 15 & 6.5 & 12 & 15.7 & 75 & 52 & 1.9 & 3.9 & 49 & 16 \\
\hline 17 & $07 / 14 / 13$ & 120.91 & 22.98 & 7 & 4.6 & 16.1 & 16.1 & 54 & 45 & 3.3 & 2.5 & 19 & 4 \\
\hline 18 & $07 / 16 / 13$ & 121.50 & 24.28 & 5 & 5.5 & 14.3 & 14 & 77 & 76 & 0.4 & 0.4 & 33 & 15 \\
\hline 19 & $07 / 24 / 13$ & 121.53 & 23.91 & 9 & 4.8 & 14.4 & 9.5 & 170 & 107 & 3.2 & 1.7 & 18 & 14 \\
\hline 20 & $07 / 24 / 13$ & 121.53 & 23.91 & 11 & 5.0 & 15.2 & 10.1 & 175 & 98 & 3.6 & 2.0 & 15 & 9 \\
\hline 21 & 09/30/13 & 120.96 & 23.85 & 11 & 4.7 & 15 & 9.4 & 75 & 74 & 1.2 & 1.9 & 20 & 15 \\
\hline 22 & $10 / 31 / 13$ & 121.35 & 23.57 & 15 & 6.4 & 15.4 & 10.5 & 140 & 129 & 7.3 & 5.6 & 25 & 19 \\
\hline 23 & $10 / 31 / 13$ & 121.40 & 23.58 & 9 & 4.6 & 13.9 & 14.5 & 121 & 121 & 2.2 & 2.7 & 12 & 3 \\
\hline 24 & $10 / 31 / 13$ & 121.38 & 23.59 & 10 & 4.6 & 12.9 & 12.9 & 134 & 108 & 1.7 & 2.5 & 13 & 4 \\
\hline 25 & $10 / 31 / 13$ & 121.43 & 23.63 & 10 & 5.1 & 16.5 & 11.1 & 155 & 90 & 1.8 & 5.6 & 20 & 10 \\
\hline 26 & $10 / 31 / 13$ & 121.44 & 23.69 & 14 & 4.8 & 14 & 14.7 & 169 & 169 & 2.0 & 1.3 & 16 & 1 \\
\hline 27 & $11 / 03 / 13$ & 121.47 & 23.68 & 10 & 4.6 & 20 & 10.4 & 156 & 73 & 1.0 & 4.2 & 21 & 14 \\
\hline 28 & $11 / 03 / 13$ & 121.47 & 23.95 & 26 & 4.9 & 15.1 & 10 & 84 & 67 & 8.9 & 3.4 & 19 & 15 \\
\hline 29 & $11 / 07 / 13$ & 121.64 & 24.06 & 10 & 4.6 & 14.2 & 14.6 & 179 & 176 & 2.8 & 0.5 & 15 & 4 \\
\hline 18 & $11 / 07 / 13$ & 121.64 & 24.06 & 10 & 4.5 & 24.1 & 13.7 & 182 & 175 & 2.1 & 1.1 & 26 & 4 \\
\hline 19 & $01 / 14 / 14$ & 120.98 & 23.86 & 15 & 5.0 & 12.2 & 12.1 & 72 & 71 & 1.1 & 1.6 & 37 & 9 \\
\hline 20 & $01 / 14 / 14$ & 121.08 & 22.89 & 8 & 5.1 & 12.1 & 11.4 & 60 & 51 & 2.6 & 3.5 & 29 & 14 \\
\hline 21 & $01 / 14 / 14$ & 121.08 & 22.88 & 8 & 5.1 & 14.4 & 14.9 & 60 & 51 & 2.5 & 3.2 & 22 & 13 \\
\hline 22 & $01 / 14 / 14$ & 121.08 & 22.89 & 8 & 4.5 & 11.7 & 11.6 & 60 & 52 & 2.8 & 3.4 & 28 & 12 \\
\hline 23 & $01 / 25 / 14$ & 121.48 & 23.79 & 12 & 4.7 & 13.8 & 13.1 & 147 & 106 & 0.8 & 2.1 & 23 & 10 \\
\hline 24 & $04 / 25 / 14$ & 121.35 & 23.55 & 18 & 4.7 & 14.3 & 11 & 115 & 76 & 3.5 & 2.3 & 18 & 10 \\
\hline 25 & $05 / 04 / 14$ & 121.65 & 23.94 & 36 & 5.2 & 12.4 & 11.9 & 188 & 146 & 4.0 & 6.8 & 21 & 9 \\
\hline 26 & $05 / 21 / 14$ & 121.43 & 23.74 & 16 & 6.0 & 10.9 & 11.2 & 133 & 81 & 3.0 & 4.4 & 21 & 11 \\
\hline 27 & $05 / 25 / 14$ & 121.16 & 23.06 & 13 & 5.0 & 16.8 & 12.4 & 92 & 90 & 3.2 & 2.4 & 15 & 5 \\
\hline 28 & $06 / 14 / 14$ & 121.53 & 23.75 & 6 & 4.6 & 16 & 16 & 177 & 174 & 1.0 & 3.3 & 26 & 6 \\
\hline 29 & $09 / 10 / 14$ & 122.06 & 24.34 & 20 & 4.7 & 13.4 & 17.6 & 222 & 218 & 10.8 & 13.4 & 23 & 1 \\
\hline 30 & $09 / 25 / 14$ & 121.27 & 22.79 & 18 & 5.3 & 16.3 & 16.2 & 102 & 109 & 1.2 & 2.7 & 26 & 5 \\
\hline 31 & $10 / 07 / 14$ & 121.58 & 23.64 & 33 & 5.2 & 18.8 & 14.5 & 183 & 161 & 4.3 & 10.2 & 26 & 8 \\
\hline
\end{tabular}


Table 1. (Continued)

\begin{tabular}{|c|c|c|c|c|c|c|c|c|c|c|c|c|c|}
\hline \multirow[b]{2}{*}{$\begin{array}{c}\text { Event } \\
\text { NO. }\end{array}$} & \multirow[b]{2}{*}{$\begin{array}{c}\text { Date }(\mathrm{mm} / \\
\text { dd/yy) }\end{array}$} & \multirow[b]{2}{*}{$\begin{array}{c}\text { Latitude } \\
\left({ }^{\circ}\right)\end{array}$} & \multirow[b]{2}{*}{$\begin{array}{l}\text { Longi- } \\
\text { tude }\left(^{\circ}\right)\end{array}$} & \multirow[b]{2}{*}{$\begin{array}{c}\text { Depth } \\
(\mathbf{k m})\end{array}$} & \multirow[b]{2}{*}{$\mathbf{M}_{\mathbf{L}}$} & \multicolumn{2}{|c|}{ Time } & \multicolumn{2}{|c|}{ Gap } & \multicolumn{2}{|c|}{ Epicenter Error } & \multicolumn{2}{|c|}{$\begin{array}{l}\text { NO. of Stations } \\
\text { for ISN-EEW }\end{array}$} \\
\hline & & & & & & $\begin{array}{l}\text { CWBSN- } \\
\text { EEW (sec) }\end{array}$ & $\begin{array}{c}\text { ISN-EEW } \\
(\mathrm{sec})\end{array}$ & $\begin{array}{l}\text { CWBSN- } \\
\text { EEW }\left({ }^{\circ}\right)\end{array}$ & $\begin{array}{c}\text { ISN-EEW } \\
\left({ }^{\circ}\right)\end{array}$ & $\begin{array}{l}\text { CWBSN- } \\
\text { EEW (km) }\end{array}$ & $\begin{array}{c}\text { ISN-EEW } \\
(\mathbf{k m})\end{array}$ & Total & Palert \\
\hline 32 & $11 / 19 / 14$ & 122.06 & 24.90 & 14 & 5.2 & 13.1 & 12.4 & 241 & 235 & 2.6 & 6.0 & 16 & 6 \\
\hline 33 & $01 / 07 / 15$ & 121.69 & 24.26 & 30 & 5.5 & 11 & 11.1 & 161 & 151 & 2.2 & 3.1 & 23 & 6 \\
\hline 34 & $01 / 16 / 15$ & 121.95 & 24.43 & 31 & 4.9 & 12.8 & 12.6 & 212 & 205 & 7.7 & 8.9 & 18 & 1 \\
\hline 35 & $01 / 02 / 13$ & 121.74 & 23.97 & 7 & 4.7 & 17.8 & 18 & 204 & 197 & 4.0 & 3.0 & 26 & 1 \\
\hline 36 & $01 / 03 / 13$ & 121.73 & 23.99 & 7 & 4.7 & 14.5 & 14.5 & 219 & 219 & 3.2 & 4.3 & 18 & 2 \\
\hline 37 & $01 / 17 / 13$ & 121.98 & 24.44 & 14 & 5.1 & 13.2 & 12.2 & 181 & 177 & 1.3 & 1.9 & 18 & 8 \\
\hline 38 & $02 / 17 / 13$ & 121.45 & 24.32 & 6 & 4.6 & 11.8 & 12.5 & 143 & 108 & 1.9 & 2.4 & 11 & 3 \\
\hline 39 & $02 / 19 / 13$ & 120.55 & 23.35 & 15 & 4.6 & 18.2 & 12.1 & 65 & 40 & 1.9 & 0.8 & 37 & 21 \\
\hline 40 & $02 / 19 / 13$ & 120.60 & 22.91 & 16 & 4.7 & 14.1 & 9.8 & 158 & 82 & 5.3 & 1.4 & 13 & 11 \\
\hline 41 & $02 / 20 / 13$ & 121.39 & 23.23 & 20 & 4.5 & 15.2 & 15.4 & 156 & 148 & 3.4 & 2.1 & 16 & 3 \\
\hline 42 & 03/04/13 & 121.33 & 23.00 & 24 & 4.6 & 14.8 & 11.1 & 177 & 173 & 4.0 & 5.4 & 16 & 4 \\
\hline 43 & $03 / 07 / 13$ & 121.46 & 24.30 & 6 & 5.9 & 14.1 & 12.1 & 69 & 69 & 1.3 & 1.1 & 16 & 4 \\
\hline 44 & 03/07/13 & 121.45 & 24.34 & 6 & 4.6 & 13.7 & 13.6 & 69 & 69 & 1.6 & 1.6 & 20 & 3 \\
\hline 45 & 03/20/13 & 121.95 & 24.45 & 12 & 4.6 & 18.9 & 19.4 & 149 & 145 & 0.5 & 2.9 & 60 & 15 \\
\hline \multirow[t]{2}{*}{46} & $03 / 27 / 13$ & 121.05 & 23.90 & 19 & 6.2 & 9.8 & 9.8 & 102 & 82 & 1.5 & 0.8 & 21 & 16 \\
\hline & & & & \multicolumn{2}{|c|}{ Average } & 14.7 & 13.1 & 139.8 & 120.7 & 3.1 & 3.4 & 22.1 & 8.2 \\
\hline
\end{tabular}

(a)

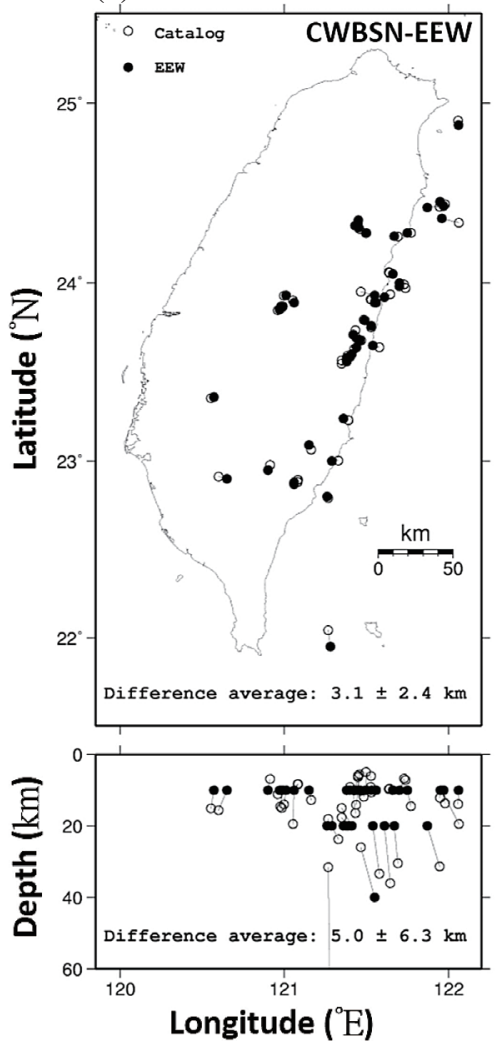

(b)

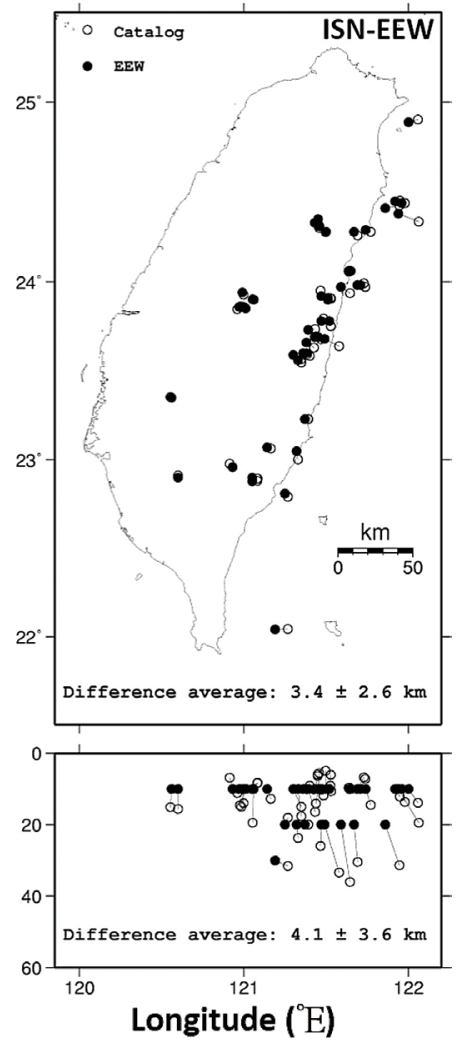

Fig. 5. The location error comparisons. (a) Comparison between the CWBSN-EEW and the CWB catalog analyzed using manual phase picking; (b) comparison between the ISN-EEW and the CWB catalog analyzed using manual phase picking. 
earthquake magnitudes $\left(\mathrm{M}_{\mathrm{Pd}_{\mathrm{d}}}\right)$ using the empirical formula of Hsiao et al. (2011). In contrast, for the Pd values from the PSN, Eq. (2) was used for estimating earthquake magnitudes. The magnitude estimations of PSN and CWSN will be averaged in ISN-EEW. Figure 6 shows a comparison of the estimated magnitudes. The estimated magnitudes from CWBSN-EEW and ISN-EEW are compared to the CWB catalog created by manual phase picking and locating. The CWBSN-EEW and the ISN-EEW have errors of 0.28 and 0.25 units, respectively. The ISN-EEW is able to provide robust earthquake magnitude estimations. The results imply that the impact of the amplified P-waves in PSN is mitigated by Eq. (2).

Comparing Figs. $7 \mathrm{a}$ and $\mathrm{b}$, the reporting times were 14.7 and $13.1 \mathrm{sec}$ for the CWBSN-EEW and ISN-EEW, respectively. Figure 8 shows comparisons of the blind-zone area distribution for each event. Some events located in the region with dense seismic stations may reduce the blind zone area to $30 \mathrm{~km}$.

\section{DISCUSSION AND CONCLUSIONS}

Using low-cost seismometers to construct a regional seismic network is an attractive solution for EEW systems. Despite the relatively low signal-to-noise ratio or artificial noise in the seismic waveforms, the $\mathrm{P}$-wave arrival times detected by the system in this study were accurate. Additionally, the amplified seismic waveforms from low-cost sensors installed onto a wall or pillar can be corrected using a regression equation. Wu et al. (2013b) demonstrated that a regional seismic network based on the Palerts system is good enough for determining earthquake location, magnitude and intensity. We further integrated PSN with the CWBSN to create a regional seismic network, ISN, with higher sensor density in Taiwan. This is the first time a traditional seismic network was integrated with a low-cost seismic network.
The off-line test result shows that the EEW system based on the ISN can reduce the reporting time and estimate accurate earthquake location and magnitude for EEW purposes.

Most EEW systems update the earthquake information along with the arrival of new data in the system. The number of triggered stations trades off the reporting time for accurate early warning. It is a challenge to decide when the updated result accuracy is good enough. One possible metric is to use GAP. Earthquakes occurring inside the seismic network present lower GAP with higher accuracy attainable for the estimated earthquake location and magnitude. However, lower GAP usually requires more stations. Earthquake localization means that the calculation should wait until more stations are triggered and the system reporting time is increased. By studying the relationship between the GAP and the number of triggered stations, we found that issuing the report when 13 stations have been triggered is appropriate for the specific condition in Taiwan based on the tradeoff between speed and accuracy in the EEW system.

A near real-time Peak Ground Acceleration (PGA) map can be obtained by the PSN within one minute from a large earthquake occurrence (Wu et al. 2002, 2013b; Hsieh et al. 2014; Wu 2015). By incorporating the PSN into the CWB$\mathrm{SN}$, the ISN can generate a PGA map with greater detail. The PGA map can be used as an indicator for the most damaged areas, the fault rupture direction and the potential aftershock distribution (Hsieh et al. 2014; Wu 2015). A dense seismic network provides another solution for earthquake magnitude determination. It is a quick and robust method for estimating earthquake magnitude using the PGA distribution area or the Pd (Lin and Wu 2010; Lin et al. 2011b). The EEW system can generate a magnitude map without locating the earthquake. In other words, the source location error will not affect the magnitude estimation procedure. The EEW system can save the time in locating earthquakes. In addition, this method is quite useful for detecting consequent earthquakes
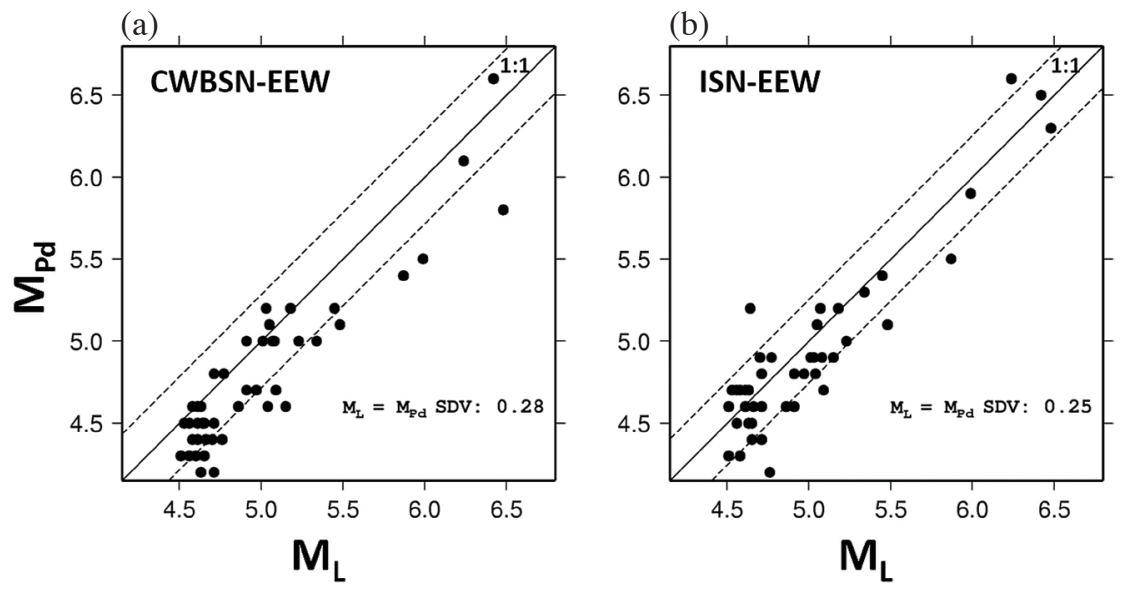

Fig. 6. The magnitude error comparisons. (a) Comparison between the CWBSN-EEW and the CWB catalog analyzed using manual phase picking; (b) comparison between the ISN-EEW and the CWB catalog analyzed using manual phase picking. 

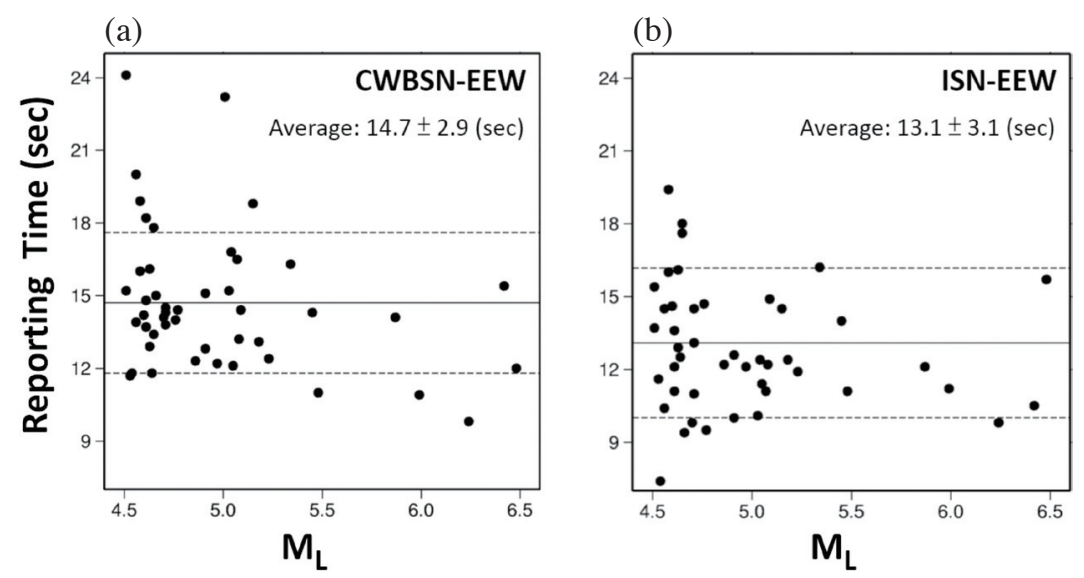

Fig. 7. Reporting time for the two EEW systems. (a) Reporting time for the CWBSN-EEW; (b) reporting time for the ISN-EEW. On average the ISN-EEW has smaller reporting time than the CWBSN-EEW.
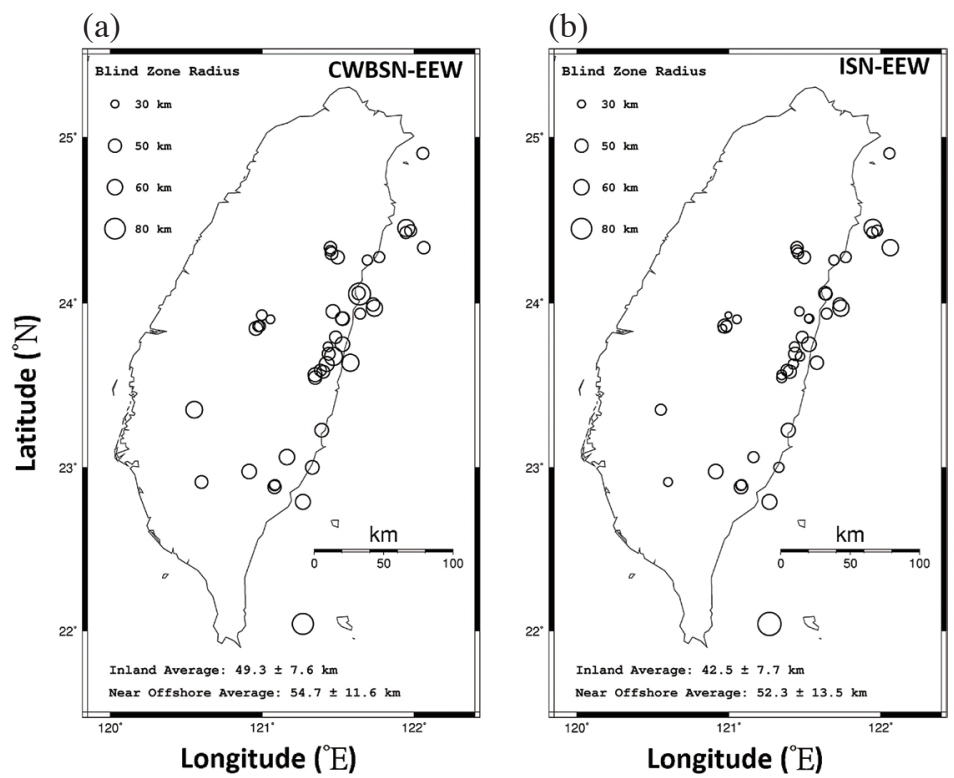

Fig. 8. Blind zone radius of the two EEW systems. (a) CWBSN-EEW blind zone radius; (b) ISN-EEW blind zone radius.

and providing warnings, especially for two consecutive earthquakes occurring within a very short time. In this case it is difficult to detect clear P-wave onset time for each event because one event's P-wave phase may be involved in the surface wave of the other event. The CWBSN-EEW or ISNEEW may fail to detect the earthquakes separately due to the phase picking problem. However, the PGA or PD distribution area can reveal the location and size of the damage. With a real-time dense seismic network this observable information will become readily available for emergency response purposes after large earthquake occurrence.

A dense seismic network provides estimated information faster and also improves the EEW system reliability. The $2011 \mathrm{M}_{\mathrm{w}} 9.0$ Tohoku earthquake demonstrated that for a large earthquake the magnitude cannot be determined using only the initial signals from several seconds (Hoshiba and Iwakiri 2011; Colombelli et al. 2012). The on-scale magnitude determination approaches such as $\mathrm{W}$-phase fast source inversion (Duputel et al. 2012) and quick $\mathrm{M}_{\mathrm{w}}$ determination using total effective shakings (Wu and Teng 2004; Lin and $\mathrm{Wu}$ 2012) could be considered in a future system.

Acknowledgements We thank Professor Jer-Ming Chiu and the Anonymous Reviewer for helpful comments that greatly improved this manuscript. The records used in this study were collected from the Central Weather Bureau Seismic Network (CWBSN) of the Taiwan. The Earthworm (Johnson et al. 1995), and GMT (Wessel and Smith 1998), and R software platforms (R Development Core Team 2011) were used in this study and are gratefully acknowledged. 
Our work was supported by the Ministry of Science and Technology, Taiwan.

\section{REFERENCES}

Allen, R. M., P. Gasparini, O. Kamigaichi, and M. Böse, 2009: The status of earthquake early warning around the world: An introductory overview. Seismol. Res. Lett., 80, 682-693, doi: 10.1785/gssrl.80.5.682. [Link]

Chang, C. H., Y. M. Wu, D. Y. Chen, T. C. Shin, T. L. Chin, and W. Y. Chang, 2012: An examination of telemetry delay in the Central Weather Bureau Seismic Network. Terr. Atmos. Ocean. Sci., 23, 261-268, doi: 10.3319/ TAO.2011.11.29.01(T). [Link]

Chen, C. H., H. H. Huang, W. A. Chao, Y. M. Wu, and C. H. Chang, 2013: Re-examining source parameters of the 2012 Wutai, Taiwan earthquake. Terr. Atmos. Ocean. Sci., 24, 827-835, doi: 10.3319/TAO.2013.05.30.01(T). [Link]

Chen, D. Y., T. L. Lin, Y. M. Wu, and N. C. Hsiao, 2012: Testing a $P$-wave earthquake early warning system by simulating the 1999 Chi-Chi, Taiwan, $M_{w} 7.6$ earthquake. Seismol. Res. Lett., 83, 103-108, doi: 10.1785/ gssrl.83.1.103. [Link]

Chen, D. Y., N. C. Hsiao, and Y. M. Wu, 2015: The Earthworm based earthquake alarm reporting system in Taiwan. Bull. Seismol. Soc. Am., 105, 568-579, doi: 10.1785/0120140147. [Link]

Chung, A. I., C. Neighbors, A. Belmonte, M. Miller, H. H. Sepulveda, C. Christensen, R. S. Jakka, E. S. Cochran, and J. F. Lawrence, 2011: The Quake-Catcher Network rapid aftershock mobilization program following the 2010 M 8.8 Maule, Chile earthquake. Seismol. Res. Lett., 82, 526-532, doi: 10.1785/gssrl.82.4.526. [Link]

Cochran, E. S., J. F. Lawrence, C. Christensen, and R. S Jakka, 2009: The quake-catcher network: Citizen science expanding seismic horizons. Seismol. Res. Lett., 80, 26-30, doi: 10.1785/gssrl.80.1.26. [Link]

Colombelli, S., A. Zollo, G. Festa, and H. Kanamori, 2012: Early magnitude and potential damage zone estimates for the great Mw 9 Tohoku-Oki earthquake. Geophys. Res. Lett., 39, L22306, doi: 10.1029/2012GL053923. [Link]

Duputel, Z., L. Rivera, H. Kanamori, and G. Hayes, 2012: $\mathrm{W}$ phase source inversion for moderate to large earthquakes (1990-2010). Geophys. J.Int., 189, 1125-1147, doi: 10.1111/j.1365-246X.2012.05419.x. [Link]

Fleming, K., M. Picozzi, C. Milkereit, F. Kühnlenz, B. Lichtblau, J. Fischer, C. Zulfikar, O. Özel, and the SAFER and EDIM working groups, 2009: The selforganizing seismic early warning information network (SOSEWIN). Seismol. Res. Lett., 80, 755-771, doi: 10.1785/gssrl.80.5.755. [Link]

Holland, A., 2003: Earthquake data recorded by the MEMS accelerometer: Field testing in Idaho. Seismol. Res. Lett., 74, 20-26, doi: 10.1785/gssrl.74.1.20. [Link]

Horiuchi, S., Y. Horiuchi, S. Yamamoto, H. Nakamura, C. Wu, P. A. Rydelek, and M. Kachi, 2009: Home seismometer for earthquake early warning. Geophys. Res. Lett., 36, L00B04, doi: 10.1029/2008GL036572. [Link]

Hoshiba, M. and K. Iwakiri, 2011: Initial 30 seconds of the 2011 off the Pacific coast of Tohoku Earthquake $\left(M_{\mathrm{w}}\right.$ 9.0)-amplitude and $\tau_{\mathrm{c}}$ for magnitude estimation for Earthquake Early Warning. Earth Planets Space, 63, 553-557, doi: 10.5047/eps.2011.06.015. [Link]

Hsiao, N. C., Y. M. Wu, T. C. Shin, L. Zhao, and T. L. Teng, 2009: Development of earthquake early warning system in Taiwan. Geophys. Res. Lett., 36, L00B02, doi: 10.1029/2008gl036596. [Link]

Hsiao, N. C., Y. M. Wu, L. Zhao, D. Y. Chen, W. T. Huang, K. H. Kuo, T. C. Shin, and P. L. Leu, 2011: A new prototype system for earthquake early warning in Taiwan. Soil Dyn. Earthq. Eng., 31, 201-208, doi: 10.1016/j. soildyn.2010.01.008. [Link]

Hsiao, N. C., T. W. Lin, S. K. Hsu, K. W. Kuo, T. C. Shin, and P. L Leu, 2014: Improvement of earthquake locations with the Marine Cable Hosted Observatory (MACHO) offshore NE Taiwan. Mar. Geophys. Res., 35, 327-336, doi: 10.1007/s11001-013-9207-3. [Link]

Hsieh, C. Y., Y. M. Wu, T. L. Chin, K. H. Kuo, D. Y. Chen, K. S. Wang, Y. T. Chan, W. Y. Chang, W. S. Li, and S. H. Ker, 2014: Low cost seismic network practical applications for producing quick shaking maps in Taiwan. Terr. Atmos. Ocean. Sci., 25, 617-624, doi: 10.3319/TAO.2014.03.27.01(T). [Link]

Huang, H. H., Y. M. Wu, T. L. Lin, W. A. Chao, J. B. H. Shyu, C. H. Chan, and C. H. Chang, 2011: The preliminary study of the 4 March $2010 \mathrm{M}_{\mathrm{w}} 6.3$ Jiasian, Taiwan earthquake sequence. Terr. Atmos. Ocean. Sci., 22, 283-290, doi: 10.3319/TAO.2010.12.13.01(T). [Link]

Huang, Y. L., B. S. Huang, K. L. Wen, Y. C. Lai, and Y. R. Chen, 2010: Investigation for strong ground shaking across the Taipei basin during the $\mathrm{M}_{\mathrm{w}} 7.0$ eastern Taiwan offshore earthquake of 31 March 2002. Terr. Atmos. Ocean. Sci., 21, 485-493, doi: 10.3319/ TAO.2009.12.11.01(TH). [Link]

Johnson, C. E., A. Bittenbinder, B. Bogaert, L. Dietz, and W. Kohler, 1995: Earthworm: A flexible approach to seismic network processing. IRIS Newsletter, 14, 1-4.

Lawrence, J. F., E. S. Cochran, A. Chung, A. Kaiser, C. M. Christensen, R. Allen, J. W. Baker, B. Fry, T. Heaton, D. Kilb, M. D. Kohler, and M. Taufer, 2014: Rapid earthquake characterization using MEMS accelerometers and volunteer hosts following the M 7.2 Darfield, New Zealand, earthquake. Bull. Seismol. Soc. Am., 104, 184-192, doi: 10.1785/0120120196. [Link]

Lin, C. C. J., Z. P. Shen, and S. K. Huang, 2011a: Predicting 
structural response with on-site earthquake early warning system using neural networks. Proceedings of the Ninth Pacific Conference on Earthquake Engineering: Building an Earthquake-Resilient Society, Auckland, New Zealand.

Lin, P.Y., 2011: Earthquake early warning systems. AUSMT, 1, 27-34, doi: 10.5875/ausmt.v1i2.123. [Link]

Lin, T. L. and Y. M. Wu, 2010: Magnitude estimation using the covered areas of strong ground motion in earthquake early warning. Geophys. Res. Lett., 37, L09301, doi: 10.1029/2010GL042797. [Link]

Lin, T. L. and Y. M. Wu, 2012: A fast magnitude estimation for the $2011 \mathrm{M}_{\mathrm{w}} 9.0$ great Tohoku earthquake. Seismol. Res. Lett., 83, 666-671, doi: 10.1785/0220110119. [Link]

Lin, T. L., Y. M. Wu, and D. Y. Chen, 2011b: Magnitude estimation using initial $\mathrm{P}$-wave amplitude and its spatial distribution in earthquake early warning in Taiwan. Geophys. Res. Lett., 38, L09303, doi: 10.1029/2011GL047461. [Link]

R Development Core Team, 2011: R: A Language and Environment for Statistical Computing, R Foundation for Statistical Computing, Vienna, Austria. Available at http://www.r-project.org/ (last accessed May 2015).

Shin, T. C., 1993: The calculation of local magnitude from the simulated Wood-Anderson seismograms of the short-period seismograms in the Taiwan area. Terr. Atmos. Ocean. Sci., 4, 155-170.

Shin, T. C. and T. L. Teng, 2001: An overview of the 1999 Chi-Chi, Taiwan, earthquake. Bull. Seismol. Soc. Am., 91, 895-913, doi: 10.1785/0120000738. [Link]

Shin, T. C., C. H. Chang, H. C. Pu, H. W. Lin, and P. L. Leu, 2013: The geophysical database management system in Taiwan. Terr. Atmos. Ocean. Sci., 24, 11-18, doi: 10.3319/TAO.2012.09.20.01(T). [Link]

Wen, K. L., Y. W. Chang, C. M. Lin, H. J. Chiang, and M. W. Huang, 2008: Damage and ground motion of the 26 December 2006 Pingtung earthquakes, Taiwan. Terr. Atmos. Ocean. Sci., 19, 641-651, doi: 10.3319/ TAO.2008.19.6.641(PT). [Link]

Wessel, P. and W. H. F. Smith, 1998: New, improved version of generic mapping tools released. Eos, Trans., $A G U, 79,579$, doi: 10.1029/98EO00426. [Link]

Wu, Y. M., 2015: Progress on development of an earthquake early warning system using low-cost sensors. Pure Appl. Geophys., 172, 2343-2351, doi: 10.1007/ s00024-014-0933-5. [Link]

Wu, Y. M. and T. L. Teng, 2002: A virtual sub-network approach to earthquake early warning. Bull. Seismol.Soc. Am., 92, 2008-2018.

Wu, Y. M. and T. L. Teng, 2004: Near real-time magnitude determination for large crustal earthquakes. Tectonophysics,390,205-216, doi: 10.1016/j.tecto.2004.03.029.
[Link]

Wu, Y. M. and L. Zhao, 2006: Magnitude estimation using the first three seconds P-wave amplitude in earthquake early warning. Geophys. Res. Lett., 33, L16312, doi: 10.1029/2006g1026871. [Link]

Wu, Y. M., T. C. Shin, C. C. Chen, Y. B. Tsai, W. H. K. Lee, and T. L. Teng, 1997: Taiwan rapid earthquake information release system. Seismol. Res. Lett., 68, 931-943, doi: 10.1785/gssrl.68.6.931. [Link]

Wu, Y. M., J. K. Chung, T. C. Shin, N. C. Hsiao, Y. B. Tsai, W. H. K. Lee, and T. L. Teng, 1999: Development of an integrated earthquake early warning system in Taiwan-case for the Hualien area earthquakes. Terr. Atmos. Ocean. Sci., 10, 719-736.

Wu, Y. M., N. C. Hsiao, T. L. Teng, and T. C. Shin, 2002: Near real-time seismic damage assessment of the rapid reporting system. Terr. Atmos. Ocean. Sci., 13, 313324.

Wu, Y. M., C. H. Chang, N. C. Hsiao, and F. T. Wu, 2003: Relocation of the 1998 Rueyli, Taiwan, earthquake sequence using three-dimensions velocity structure with stations corrections. Terr. Atmos. Ocean. Sci., 14, 421430.

Wu, Y. M., H. Y. Yen, L. Zhao, B. S. Huang, and W. T. Liang, 2006: Magnitude determination using initial $P$ waves: A single-station approach. Geophys. Res. Lett., 33, L05306, doi: 10.1029/2005GL025395. [Link]

Wu, Y. M., C. H. Chang, L. Zhao, T. L. Teng, and M. Nakamura, 2008: A comprehensive relocation of earthquakes in Taiwan from 1991 to 2005. Bull. Seismol. Soc. Am., 98, 1471-1481, doi: 10.1785/0120070166. [Link]

Wu, Y. M., T. L. Lin, W. A. Chao, H. H. Huang, N. C. Hsiao, and C. H. Chang, 2011: Faster short-distance earthquake early warning using continued monitoring of filtered vertical displacement: A case study for the 2010 Jiasian, Taiwan, earthquake. Bull. Seismol. Soc. Am., 101, 701-709, doi: 10.1785/0120100153. [Link]

Wu, Y. M., C. H. Chang, H. Kuo-Chen, H. H. Huang, and C. Y. Wang, 2013a: On the use of explosion records for examining earthquake location uncertainty in Taiwan. Terr. Atmos. Ocean. Sci., 24, 685-694, doi: 10.3319/ TAO.2013.01.31.01(T). [Link]

Wu, Y. M., D. Y. Chen, T. L. Lin, C. Y. Hsieh, T. L. Chin, W. Y. Chang, W. S. Li, and S. H. Ker, 2013b: A highdensity seismic network for earthquake early warning in Taiwan based on low cost sensors. Seismol. Res. Lett., 84, 1048-1054, doi: 10.1785/0220130085. [Link]

Yu, S. B., H. Y. Chen, and L. C. Kuo, 1997: Velocity field of GPS stations in the Taiwan area. Tectonophysics, 274, 41-59, doi: 10.1016/S0040-1951(96)00297-1. [Link] 